\title{
Creep Behavior of Saturated Clay in Triaxial Test and a Hyperbolic Model
}

\author{
Bin Xiao $\mathbb{D}^{1,2}$ Minyun Hu $\mathbb{D}^{1},{ }^{1}$ Peijiao Zhou $\mathbb{D}^{3}$, Yuke Lu $\mathbb{D}^{1},{ }^{1}$ and Yong Zhang $\mathbb{D}^{1}$ \\ ${ }^{1}$ Department of Civil Engineering, Zhejiang University of Technology, Hangzhou, China 310014 \\ ${ }^{2}$ Zhejiang Tongji Science and Technology Vocational College, Hangzhou, China 311231 \\ ${ }^{3}$ Zhejiang College of Construction, Hangzhou, China 311231
}

Correspondence should be addressed to Minyun Hu; huminyun@zjut.edu.cn

Received 8 July 2021; Accepted 19 October 2021; Published 16 November 2021

Academic Editor: José Luis Pastor

Copyright (c) 2021 Bin Xiao et al. This is an open access article distributed under the Creative Commons Attribution License, which permits unrestricted use, distribution, and reproduction in any medium, provided the original work is properly cited.

As one of the basic mechanical properties of soil, the creep property of a given type soil is related to stress path, and stress level. In this paper, triaxial shear creep tests under different deviatoric stress levels were performed on both intact sample and the reconstituted sample of clay taken from Hangzhou, China. Based on the Boltzmann linear superposition principle, the creep curves of the clay sample under different levels of deviatoric stress were obtained, and the creep characteristics of the intact sample and the reconstituted sample were compared in both total stress creep analysis and effective stress creep analysis. Furthermore, the creep curves were fitted using a hyperbolic creep model. The results show that (1) under the same stress level, the creep of intact sample evolves more than that of reconstituted sample; (2) the hyperbolic creep model is suited to describe the creep characteristics of intact and reconstituted clay, and the model parameters $A_{\mathrm{s}}$ and $B_{\mathrm{s}}$ can be linearly correlated to the stress level $D_{\mathrm{r}}$; (3) for the application of the hyperbolic model, the total stress analysis works better, and the model parameters $A_{\mathrm{s}}$ and $B_{\mathrm{s}}$ can be determined by a linear relationship with Dr.

\section{Introduction}

Creep is a macroscopic reflection of time effect of soil's deformation due to stress change. It can lead to long-term settlement of building foundation and road embankment, which may cause adverse impact on the serviceability of buildings and the maintenance of highways. As compared to sandy soils, the creep of clayey soils is considerable and cannot be neglected, so it is essential to investigate the creep characteristics of saturated clays.

Previous experimental studies [1-5] have shown that the creep character of soil depends on soil's structure and is affected by its sedimentation history and deposition environment. Moreover, the loading path and stress level also affect the soil creep characteristics $[6,7]$. For example, in onedimensional (1-D) compression and consolidation test, a soil sample creeps in one dimension and the creep will be affected by soil's stiffness and the stress level $[8,9]$. However, in triaxial test, a soil sample may deform in three directions, and the induced volume change and excess pore pressure dissipation are associated to the drainage condition $[5,10]$, so the creep characteristics are loading path dependent.

To predict the deformation process of soil ground under an applied loading, it is necessary to establish creep model which is suitable for various stress conditions. Based on the 1-D compression creep test of Hong Kong marine reconstituted clay, Yin [11] proposed a nonlinear creep model with logarithmic time as a variable. By carrying out triaxial creep tests of soils under different stress levels, Singh and Mitchell [12] put forward a Singh-Mitchell empirical stress creep model, in which the exponential function is used to describe the relationship between stress and strain, and the power function is used to describe the relationship between strain and time. However, the model performs poorly when the deviatoric stress level is lower than $20 \%$ or higher than $80 \%$. Mesri et al. [13] proposed creep model using two nonlinear functions to describe the stress-strain and strain-time relationship, respectively. Lu et al. [14] conducted a series of 


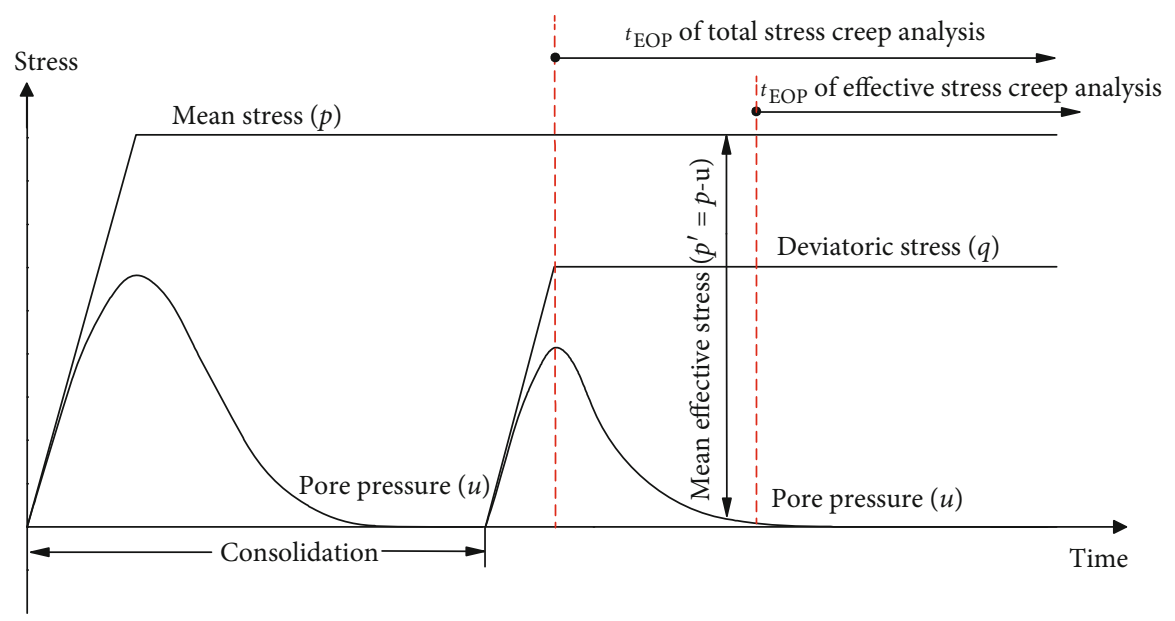

Figure 1: Total stress creep and effective stress creep.

TABLE 1: Physical index of soil samples.

\begin{tabular}{|c|c|c|c|c|c|c|c|}
\hline Soil type & $\begin{array}{l}\text { Depth } \\
(\mathrm{m})\end{array}$ & $\begin{array}{c}\text { Specific Gravity } \\
\text { Gs }\end{array}$ & $\begin{array}{c}\text { Water content } \\
\mathrm{w}(\%)\end{array}$ & $\begin{array}{c}\text { Void ratio } \\
\mathrm{e} 0\end{array}$ & $\begin{array}{l}\text { Liquid limit } \mathrm{wL} \\
(\%)\end{array}$ & $\begin{array}{c}\text { Plastic limit wP } \\
(\%)\end{array}$ & $\begin{array}{l}\text { Density } \\
\left(\mathrm{g} / \mathrm{cm}^{3}\right)\end{array}$ \\
\hline Intact clay & \multirow{2}{*}{$20-25$} & \multirow{2}{*}{2.74} & 31.1 & \multirow{2}{*}{0.892} & \multirow{2}{*}{39.20} & \multirow{2}{*}{22.00} & 1.898 \\
\hline Reconstituted clay & & & 28 & & & & 1.854 \\
\hline
\end{tabular}

triaxial consolidation undrained creep tests on Hunan roadbed soft soil and proposed an undrained creep formula. Based on the experements of the triaxial shear creep test on reconstituted clays and by comparing different creep models, Xiao [15] proposed a hyperbolic creep model by considering the drainage condition.

In order to discuss the creep characteristics of clay, it is necessary to clarify the relationship between consolidation and creep of clay. There are two viewpoints: one point assumes that thecreep and the consolidation deformation of clay are coupled and occur simultaneously; anotherpoint assumes that there is no creep occurrence during consolidation process, i.e., creep happens afterconsolidation. In the triaxial shear test, the total mean stress $p\left(\left(\sigma_{1}+2 \sigma_{3}\right) / 3\right)$ is taken by the soil skeleton and pore water, while the deviatoric stress $q\left(\sigma_{1}-\sigma_{3}\right)$ is taken only by the soil skeleton. Therefore, there are two methods for deviatoric strain creep analysis according to the two points, respectively: the first one is the total stress creep (TSC) analysis, in which the time when the total mean stress and the deviatoric stress remains unchanged is set as the starting point of creep; the second one is the effective stress creep (ESC) analysis, in which the time, when the effective mean stress and the deviatoric stress remain unchanged, is set as the starting point of creep, as shown in Figure 1.

From the above analysis, in order to investigate the creep characteristics of specific clay and to establish an applicable creep model, it is necessary to carry out laboratory experiments simulating real loading process. In this paper, triaxial shear creep tests were carried out on the intact sample and the reconstituted sample of a saturated clay, respectively, taken from Hangzhou Bay area, China. Total stress creep analysis and effective stress creep analysis were applied to study the creep characteristics of intact clay and reconsti-
TABle 2: Triaxial creep test plan.

\begin{tabular}{|c|c|c|}
\hline Soil type & $\begin{array}{c}\text { Shear strength in CU test } \\
(\mathrm{qf} / \mathrm{kPa})\end{array}$ & Loading steps $(\mathrm{q} / \mathrm{kPa})$ \\
\hline Intact clay & 430 & $\begin{array}{c}60-120-180-240-300- \\
360-420\end{array}$ \\
\hline $\begin{array}{l}\text { Reconstituted } \\
\text { clay }\end{array}$ & 330 & $60-120-180-240-300$ \\
\hline
\end{tabular}

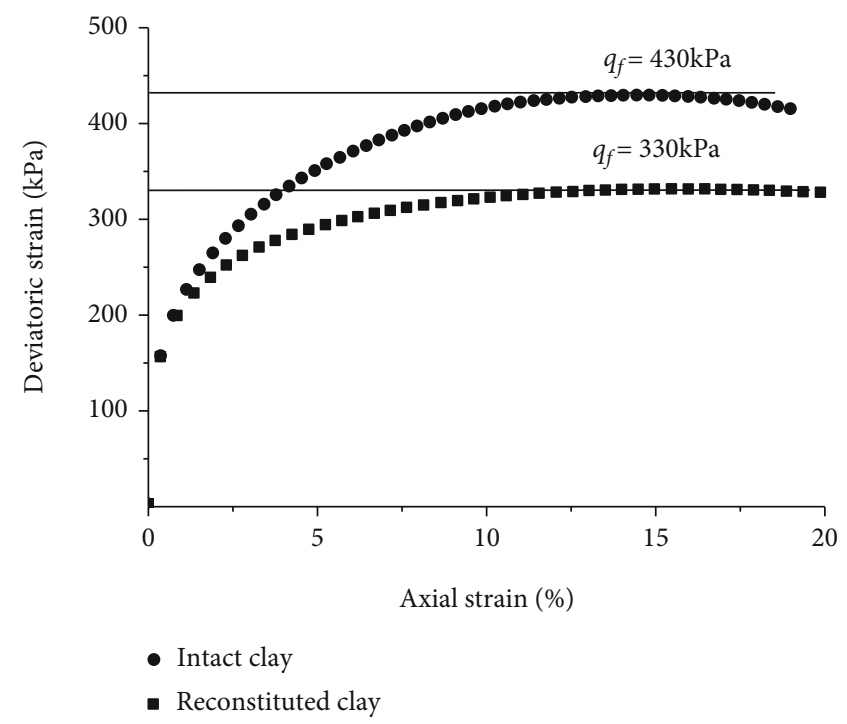

Figure 2: Triaxial consolidation undrained (CU) test.

tuted clay under different stress levels. Then, an empirical creep model of saturated clay was proposed for use in practice. 


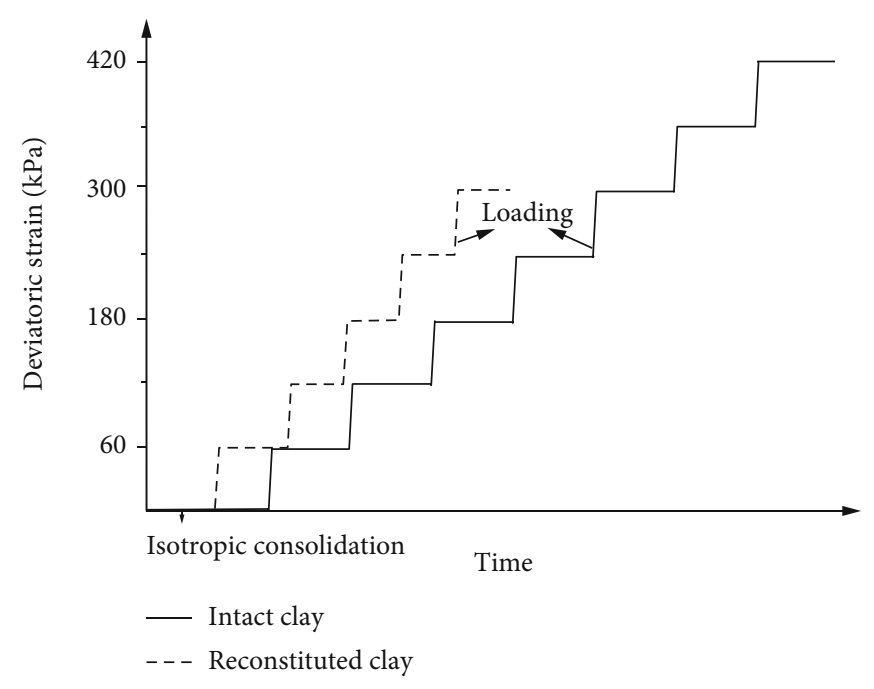

FIgURE 3: Stress path of creep test.

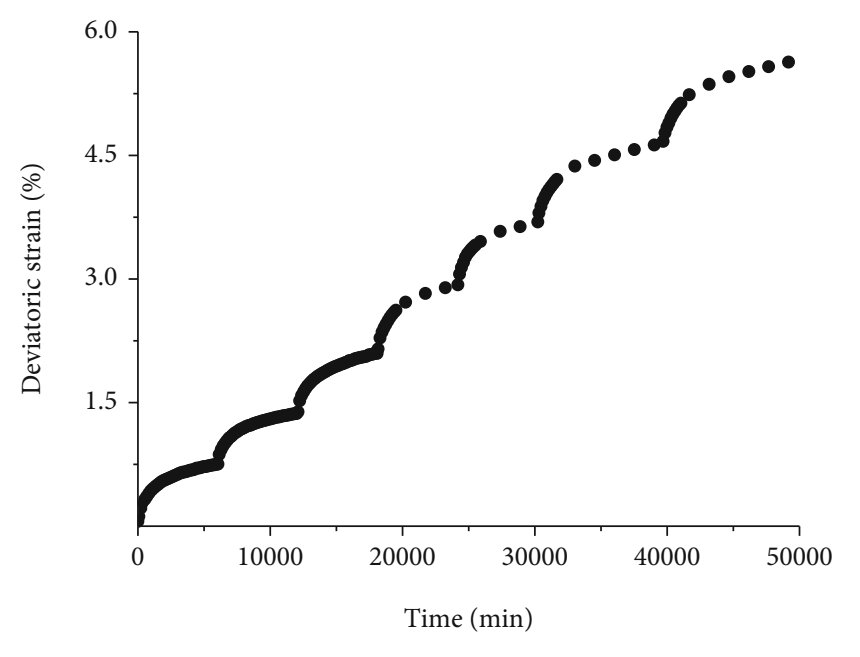

- Intact clay

FIgURE 4: Whole process curve of the triaxial deviatoric strain of intact soil.

\section{Soil Sample Preparation and Test Plan}

2.1. Soil Sample Preparation. The soil sample was taken from a depth of $20-25 \mathrm{~m}$ below the surface of an engineering site in Hangzhou, China, and was judged to be saturated clay. The physical index is shown in Table 1. The intact sample was obtained using the soil drilling extractor; the original structure was maintained during sample preparation. The reconstituted clay sample was made by compacting the soil with a water content of $28 \%$, layer by layer into the sample preparation mould, and its dry density was the same as the intact clay soil. The dimension of the cylindrical sample used in the triaxial test is $H \times D=$ $76 \times 38 \mathrm{~mm}$. The room temperature was controlled to be $24 \pm 1^{\circ} \mathrm{C}$ during the test.

2.2. Test Method. In this test, the GDS triaxial apparatus was adopted, by which the resolution of strain measurement can reach 10-5. After the soil sample was saturated to be $95 \%$, it was then isotropically consolidated under the pressure of $\mathrm{p}^{\prime}=400 \mathrm{kPa}$. After the consolidation, the deviatoric stress was increased in steps to the prescribed levels under drained condition. The strain development was monitored under different levels of deviatoric stress.

To examine the effect of soil's structure on creep characteristics, the intact and the reconstituted soil sample were both tested by the same procedures but with different loading steps, as shown in Table 2. Under consolidated undrained shearing the strength $q_{\mathrm{f}}$ of intact sample and reconstituted clay were $430 \mathrm{kPa}$ and $330 \mathrm{kPa}$, respectively, as shown in Figure 2. The loading scheme was designed accordingly (as shown in Table 2). The time process of loading for two samples are shown in Figure 3. The loading time for each level of deviatoric stress was adjusted according to the pore pressure dissipation to ensure development of secondary consolidation. For each loadingstep, the stress state retained until the axial strain rate is less than $0.0001 / \mathrm{d}$ insecondary consolidation process. 


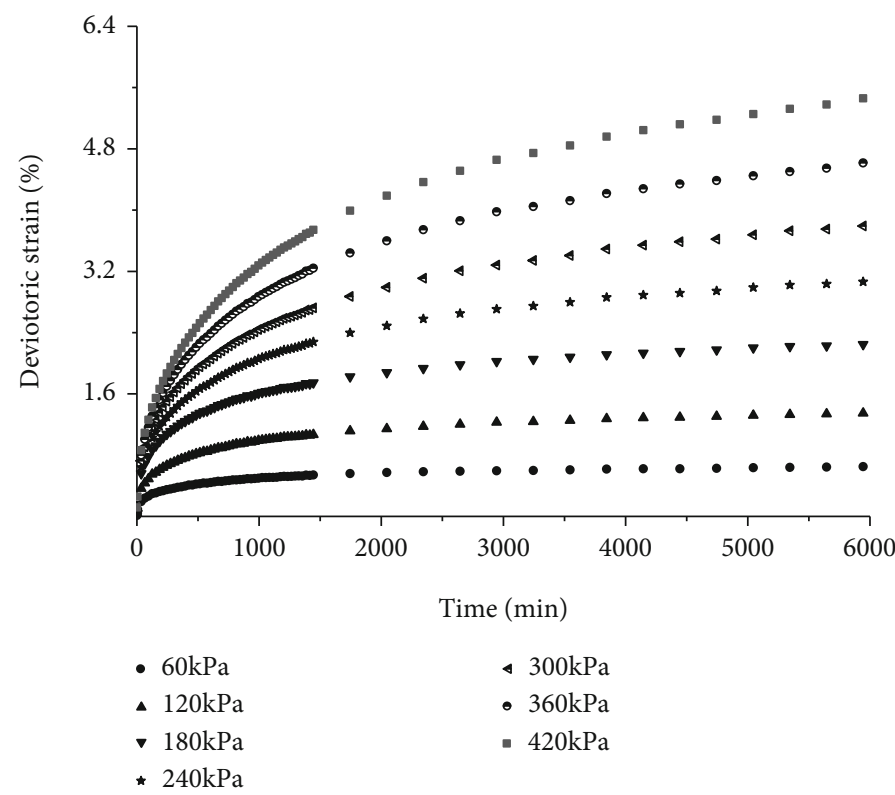

FIGURE 5: Deviatoric strain creep curve of intact soil.

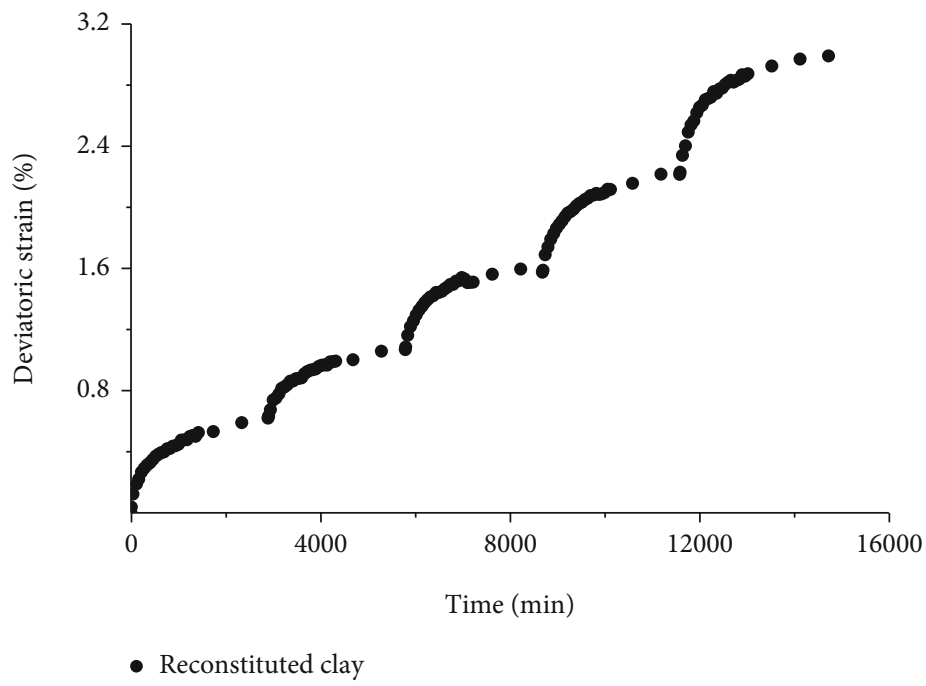

FIGURE 6: Whole process curve of triaxial deviatoric strain evolution of reconstituted soil.

\section{Test Results and Analysis}

\subsection{Total Stress Creep Analysis}

(1) While analysing the total stress creep of the intact sample, the shear creep test is divided into 7 levels. As shown in Figure 4, under each level of deviatoric stress, the deviatoric strain of the intact sample showed a nonlinear variation with time. As the deviatoric stress increased, the strain increment over time also increased

By superimposing the test curves using Boltzmann's linear superposition principle [3], the strain-time curve of the intact sample under each deviatoric stresse can be obtained and shown in Figure 5. It can be seen that as the deviatoric stress level was increased, the deviatoric strain creep evolves more and in a longer time.

(2) While analysing the total stress creep of the reconstituted sample, the shear creep was divided into 5 levels. As shown in Figure 6, the deviatoric strain rate of the reconstituted sample also exhibited nonlinear attenuation characteristics; with the increase of the stress level, the increment of strain obviously increased. By applying the Boltzmann linear superposition principle, the total stress creep curves of the reconstituted sample under different deviatoric stresses is shown in Figure 7. It can be seen that the greater the deviatoric stress, the greater the deviatoric strain creep evolvement, and the longer it takes the creep to become stable 


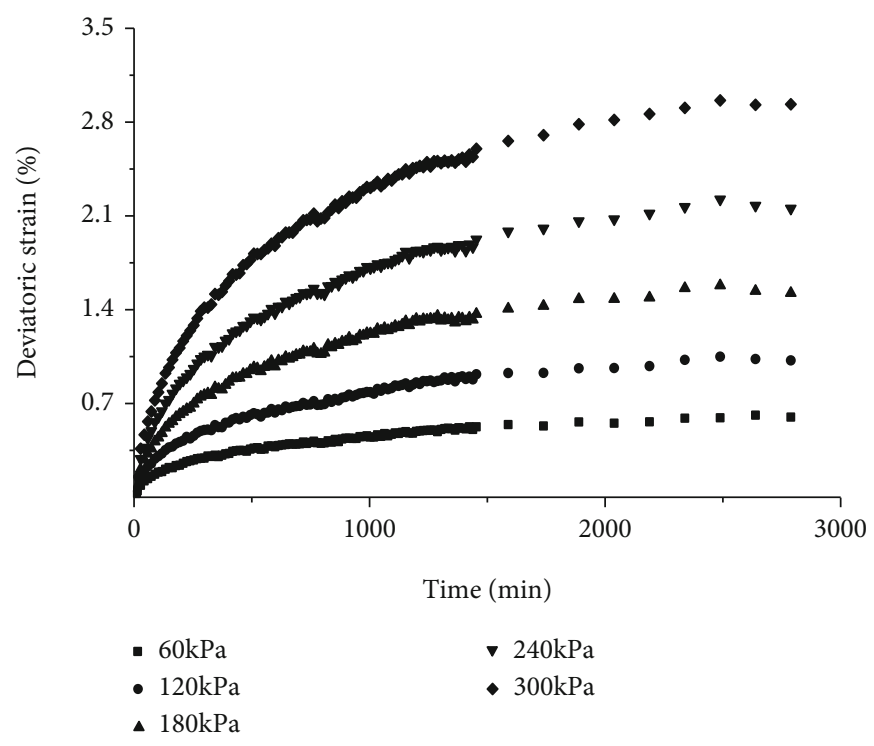

FIgURE 7: Deviatoric strain creep curve of reconstituted soil.

By comparing the whole curves of the deviatoric strain (Figures 4 and 6) and the creep curves (Figures 5 and 7) under different deviatoric stresses, it can be found that both intact clay and reconstituted clay samples exhibit similar creep characteristics. However, for the same deviatoric stress level, the creep of intact clay sample gave a larger strain evolvement than reconstitutued sample, and a shorter time to be stabilized in creep process.

\subsection{Effective Stress Creep Analysis}

(1) There are two methods of dividing primary and secondary consolidation: one method is based on pore pressure dissipation analysis, where the cut off time can be determined when consolidation degree reaches $95 \%$, which is also known as the starting time of effective stress creep; the other method is based on $e$ - $p$ curve analysis, where $t_{\mathrm{EOP}}$ can be determined according to the curvature change in $e-\log p$ curve $[20,21]$, as shown in Figure $8, t_{\mathrm{EOP}}$ was determined by pore pressure-logt curve.

Tables 3 and 4 show the division results of the intact sample and the reconstituted sample, respectively, by both methods. It can be found that

(i) For intact and reconstituted samples, the $t_{\mathrm{EOP}}$ determined by the curve analysis method was shorter than that of the pore pressure dissipation method, and the corresponding consolidation degree of the intact sample and the reconstituted sample $t_{\mathrm{EOP}}$ was averaged about $80 \%$ and $70 \%$, respectively. Considering that the permeability coefficient of the sample will change during consolidation and the primary and secondary consolidations will be coupled to some extend, the curve characteristic method is acceptable and then applied to later analysis

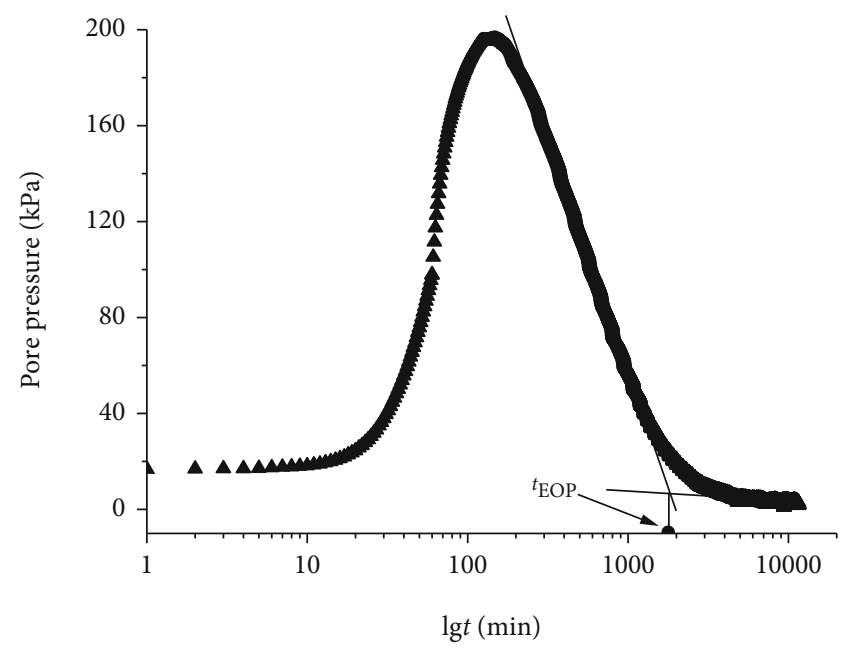

Figure 8: Curve analysis method to determine $t_{\mathrm{EOP}}$.

(ii) In both division method analysis, the starting time of secondary consolidation of the intact sample seems later than that of the reconstituted sample, indicating the impact of soil's initial structure

(iii) The higher the deviatoric stress level, the later the starting time of the secondary consolidation

Based on the above analysis, the curve analysis method was suggested to determine the effective stress creep starting point of saturated clay.

(2) Effective stress and creep analysis. Figures 9 and 10 show the deviatoric strain and creep curves of intact sample and reconstituted sample using the curve analysis method, respectively. It can be found that 1) for intact sample and reconstituted sample, the higher the deviatoric stress level, the more the creep evolvement and the higher the creep rate;2) in the 
TABLE 3: $t_{\mathrm{EOP}}$ value and pore pressure dissipation degree $\left(u_{0}-u\right) / u_{0} \times 100 \%$ of intact samples.

\begin{tabular}{|c|c|c|c|c|c|}
\hline \multirow{2}{*}{ Soil type } & \multirow{2}{*}{ Deviatoric stress $(\mathrm{kPa})$} & \multicolumn{2}{|c|}{ Curve analysis method } & \multicolumn{2}{|c|}{ Pore pressure dissipation method } \\
\hline & & $t_{\mathrm{EOP}}(\min )$ & $\left(u_{0}-u / u_{0}\right) \times 100 \%$ & $t_{\mathrm{EOP}}(\min )$ & $\left(u_{0}-u / u_{0}\right) \times 100 \%$ \\
\hline \multirow{7}{*}{ Intact samples } & 60 & 1335 & 73.90 & 2778 & 95 \\
\hline & 120 & 2028 & 77.20 & 3250 & 95 \\
\hline & 180 & 2186 & 81.60 & 3763 & 95 \\
\hline & 240 & 2816 & 83.47 & 3914 & 95 \\
\hline & 300 & 2839 & 86.09 & 4215 & 95 \\
\hline & 360 & 3714 & 87.74 & 4333 & 95 \\
\hline & 420 & 4078 & 86.73 & 4747 & 95 \\
\hline
\end{tabular}

Note: $u_{0}$ represents the maximum pore pressure and $u$ is the corresponding pore pressure at $t_{\mathrm{EOP}}$.

TABLE 4: $t_{\mathrm{EOP}}$ value and pore pressure dissipation degree $\left(u_{0}-u\right) / u_{0} \times 100 \%$ of reconstituted samples.

\begin{tabular}{|c|c|c|c|c|c|}
\hline \multirow{2}{*}{ Soil type } & \multirow{2}{*}{ Deviatoric stress $(\mathrm{kPa})$} & \multicolumn{2}{|c|}{ Curve analysis method } & \multicolumn{2}{|c|}{ Pore pressure dissipation method } \\
\hline & & $t_{\mathrm{EOP}}(\min )$ & $\left(u_{0}-u / u_{0}\right) \times 100 \%$ & $t_{\mathrm{EOP}}(\min )$ & $\left(u_{0}-u / u_{0}\right) \times 100 \%$ \\
\hline \multirow{5}{*}{ Reconstituted samples } & 60 & 682 & 72.97 & 1793 & 95 \\
\hline & 120 & 903 & 69.12 & 2018 & 95 \\
\hline & 180 & 1080 & 63.48 & 2158 & 95 \\
\hline & 240 & 1289 & 65.96 & 2501 & 95 \\
\hline & 300 & 1286 & 64.71 & 2661 & 95 \\
\hline
\end{tabular}

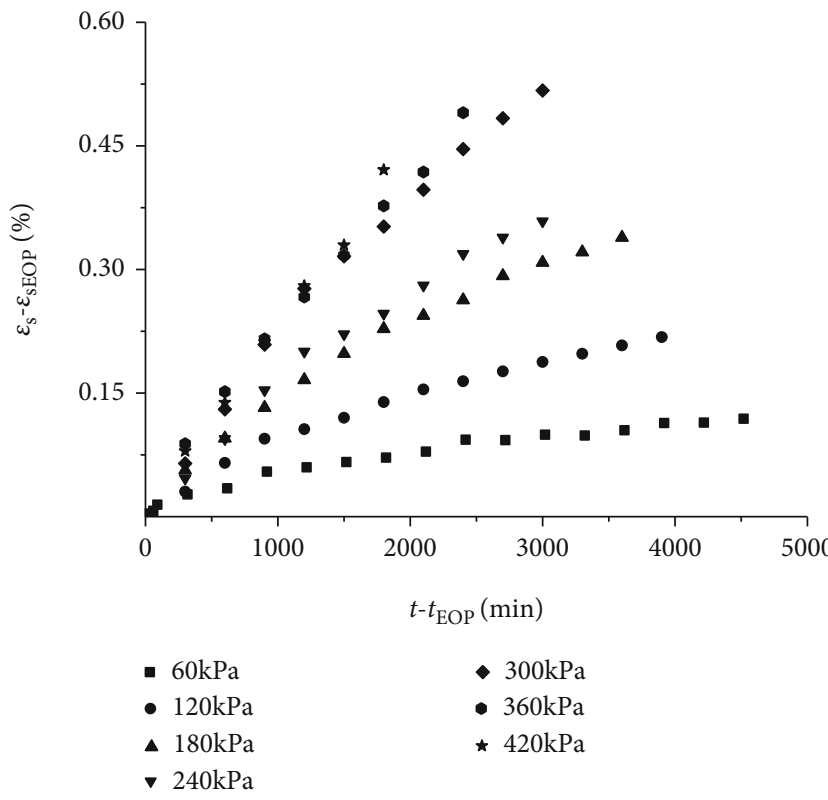

FIgURE 9: Deviatoric strain creep curve of the intact sample.

secondary consolidation stage, the development of the deviatoric strain of intact sample differs from that of the reconstituted sample

\section{Creep Model and Parameter Analysis of Saturated Clay}

4.1. Establishment of Hyperbolic Creep Model. Based on theory, experience, quasitheoretical, and quasiexperience, researchers proposed creep models suitable for different types of soils [11-20]. In this paper, two models (Yin's

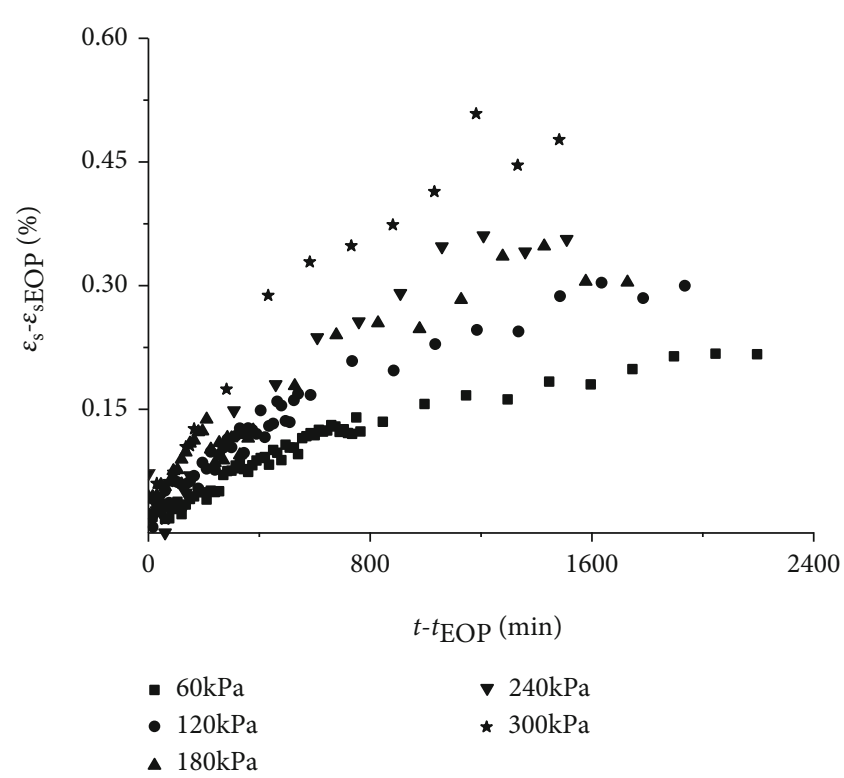

FIGURE 10: Deviatoric strain creep curve of reconstituted soil.

model [11] and Singh-Mitchell model [12]) commonly used to describe the creep characteristics of soft clay were selected to fit the creep curves of intact soil. As shown in Figure 11, when the stress level is low, both models can be used to fit the creep curve of intact samples. However, when the stress level is high, the fitting accuracy of Singh-Mitchell model becomes low, while Yin's model cannot apply. The application of the two models to creep curves of intact soil seems not satisfactory.

Based on test results, the hyperbolic creep model proposed by Xiao [15] was used to fit the creep characteristics of the intact and reconstituted sample, as follows: 


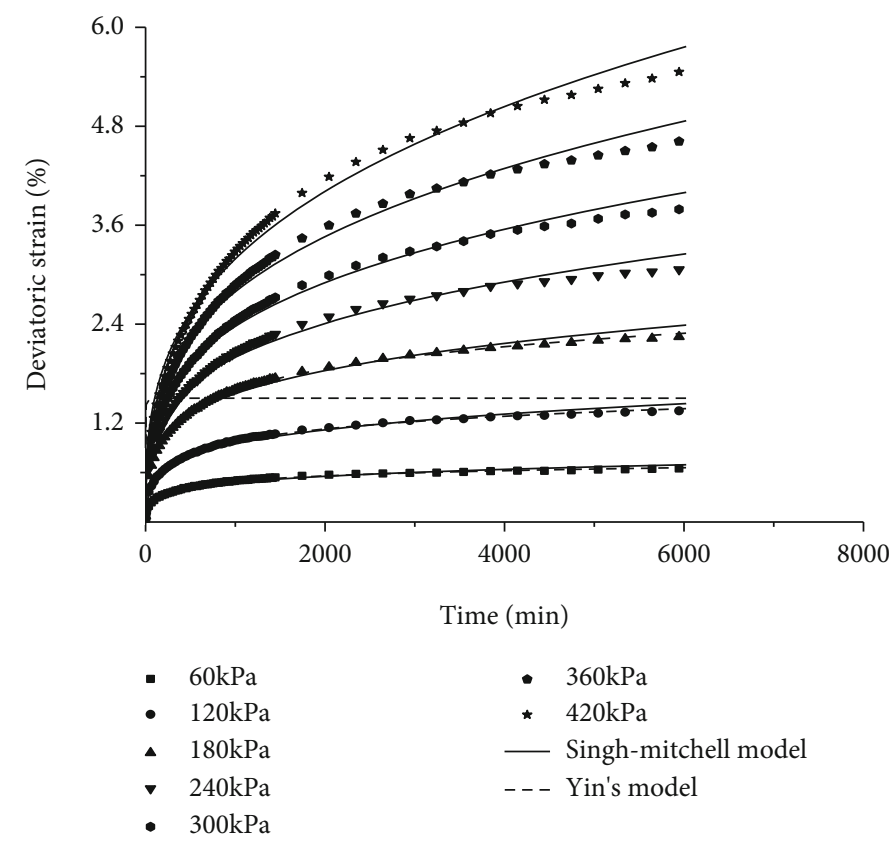

FIgURe 11: Fitting curves of intact soil by the Singh-Mitchell model and Yin's model.

$$
\varepsilon_{s}(t)-\varepsilon_{s}\left(t_{0}\right)=A_{s} \frac{t-t_{0}}{B_{s}+\left(t-t_{0}\right)},
$$

where $\varepsilon_{s}(t)$ represents the deviatoric strain of the sample at time $t ; \varepsilon_{s}\left(t_{0}\right)$ represents the deviatoric strain of the sample at a time $t_{0} ; t_{0}$ is the reference time; $A_{s}$ is the final deviatoric strain of creep; when $t \longrightarrow \infty, A_{s}=\varepsilon_{s}(\infty)-\varepsilon_{s}\left(t_{0}\right)$; and $B_{s}$ is the characteristic time of creep of a soil, which is the time when the creep reaches $50 \%$ of the total creep.

\subsection{Fitting Analysis of Total Stress Creep}

(1) Based on the triaxial test results of the intact sample, the creep curves of the intact sample under multiple deviatoric stress levels were fitted using the hyperbolic empirical model, as shown in Figure 12. It can be found that the hyperbolic creep model can fit well the total stress creep process of the intact sample. Table 5 gives the parameters of hyperbolic model by fitting intact clay sample under different deviatoric stresses, and shows the accuracy of the model is highly satisfying. As the stress level $D_{\mathrm{r}}=($ $\left.\sigma_{1}-\sigma_{3}\right) /\left(\sigma_{1}-\sigma_{3}\right)_{f}$ increases, and fitting parameters $A_{\mathrm{s}}$ and $B_{\mathrm{s}}$ are positively correlated with the stress level

(2) The creep curves of the reconstituted sample under multiple deviatoric stress levels were fitted using the hyperbolic empirical model and shown in Figure 13. According to the fitting analysis given in Table 6, it can be seen that the fitting accuracy is also satisfactory. As the stress level increases, $A_{\mathrm{s}}$ and $B_{\mathrm{s}}$ increase as well, exhibiting similar correlation between model parameters and stress level to the intact sample

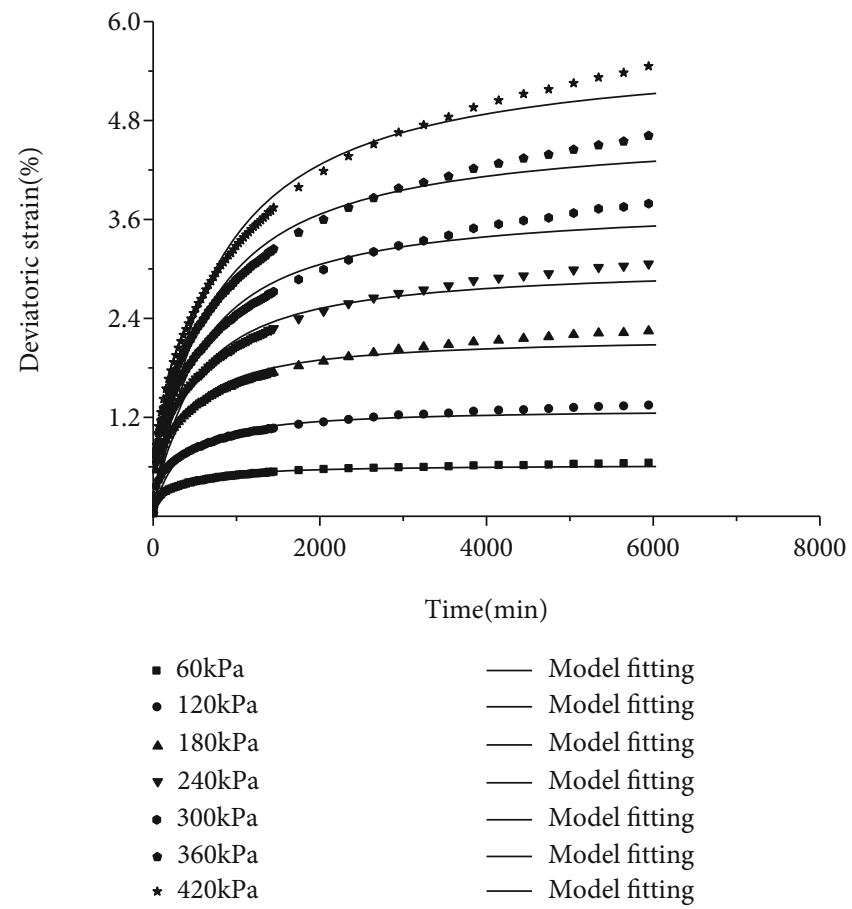

Figure 12: Fitting curves of total stress creep curve of intact soil.

(3) Based on the model fitting results given in Tables 5 and 6, Figure 14 shows the relationship between the model parameters $A_{\mathrm{s}}$ and $D_{\mathrm{r}}$. It can be seen that for both intact sample and reconstituted sample, the final deviatoric strain creep $A_{\mathrm{s}}$ increases with the deviatoric stress level; Under the same stress level, the final deviatoric strain creep of the intact sample 
TABLE 5: Hyperbolic model parameters and correlation coefficient $R^{2}$ of triaxial creep test (intact clay).

\begin{tabular}{lcccc}
\hline Deviatoric stress $(\mathrm{kPa})$ & Deviatoric stress level $D_{\mathrm{r}}$ & $A_{\mathrm{s}}(\%)$ & $B_{\mathrm{s}}(\mathrm{min})$ & Correlation coefficient $R^{2}(\%)$ \\
\hline 60 & 0.14 & 0.63 & 215.82 & 96.76 \\
120 & 0.28 & 1.31 & 278.18 & 96.39 \\
180 & 0.42 & 2.20 & 307.76 & 96.39 \\
240 & 0.56 & 3.06 & 426.34 & 96.79 \\
300 & 0.70 & 3.81 & 497.59 & 96.68 \\
360 & 0.84 & 4.72 & 578.34 & 97.19 \\
420 & 0.98 & 5.70 & 674.58 & 97.57 \\
\hline
\end{tabular}

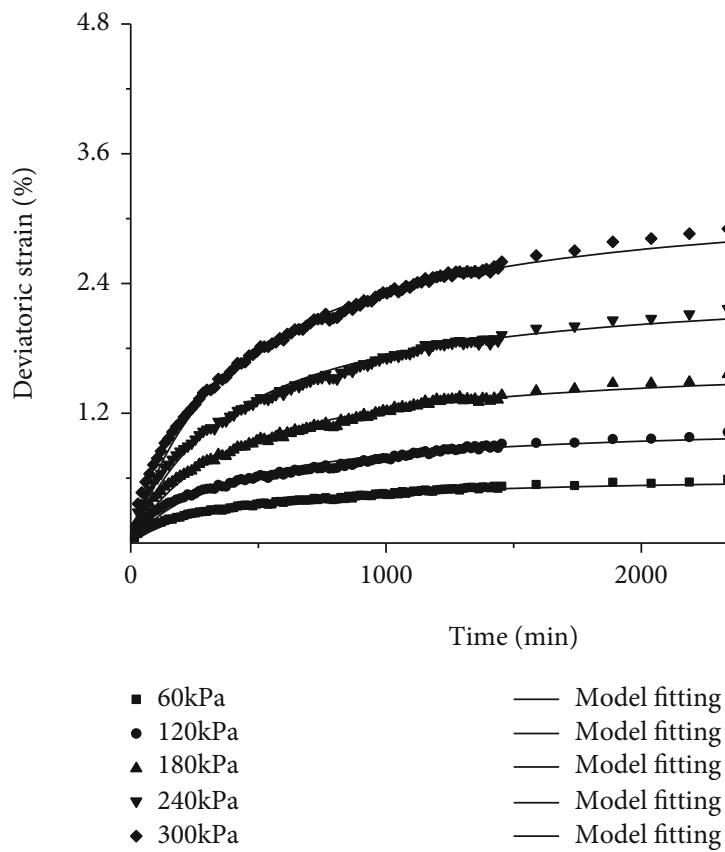

FIGURE 13: Fitting curves of total stress creep curve of reconstituted soil.

TABLE 6: Hyperbolic model parameters and correlation coefficient $R^{2}$ of triaxial creep test (reconstituted clay).

\begin{tabular}{lcccc}
\hline Deviatoric stress $(\mathrm{kPa})$ & Deviatoric stress level $D_{\mathrm{r}}$ & $A_{\mathrm{s}}(\%)$ & $B_{\mathrm{s}}(\mathrm{min})$ & Correlation coefficient $R^{2}(\%)$ \\
\hline 60 & 0.18 & 0.63 & 367.21 & 97.77 \\
120 & 0.36 & 1.12 & 379.50 & 98.08 \\
180 & 0.55 & 1.71 & 388.81 & 98.90 \\
240 & 0.73 & 2.43 & 404.11 & 99.14 \\
300 & 0.91 & 3.28 & 416.40 & 99.39 \\
\hline
\end{tabular}

was greater than that of the reconstituted sample. Figure 15 shows the relationship between the model parameters $B_{\mathrm{s}}$ and $D_{\mathrm{r}}$. It can be found that $B_{\mathrm{s}}$ increased with stress level Dr for intact clay, while $B_{\mathrm{s}}$ of reconstituted clay changes over a narrow range with stress level increased between $0 \sim 1$. On average, $B$ s is about $400 \mathrm{~min}$

It can be seen from Figures 14 and 15 that the model parameters, $A_{\mathrm{s}}$ and $B_{\mathrm{s}}$, of both the intact sample and the reconstituted sample are in a linear correlation with the stress level $D_{\mathrm{r}}$. The linear fitting relationship is given in equations (2)-(5).

$$
\text { Intact clay : } A_{s}=5.6 * D_{\mathrm{r}} \text {, }
$$

Intact clay : $B_{s}=554.51 * D_{\mathrm{r}}+116.02$,

Reconstituted clay : $A_{s}=3.41 * D_{\mathrm{r}}$, 




Figure 14: Model parameter $A_{\mathrm{s}}$ versus deviatoric stress level $D_{\mathrm{r}}$.



FIgURE 15: Model parameter $B_{\mathrm{s}}$ versus deviatoric stress level $D_{\mathrm{r}}$.

Reconstituted clay : $B_{s}=67.64 * D_{\mathrm{r}}+354.31$.

\subsection{Fitting Analysis of Effective Stress Creep}

(1) According to the fitted effective stress creep curves of the intact sample under different stress levels using the hyperbolic creep model (Figure 16), model parameters are extracted into Table 7 . The fitting accuracy is higher than $99 \%$. The parameters $A_{\mathrm{s}}$ and $B_{\mathrm{s}}$ of the intact sample increases with the stress level. It needs to be noticed that when the deviatoric stress level $D_{\mathrm{r}}$ reached $98 \%$, although the accuracy of the hyperbolic model fitting was still very good, the creep parameters $A_{\mathrm{s}}$ and $B_{\mathrm{s}}$ of the intact sample were greatly increased, suggesting that when the deviatoric stress is close to the failure value, the shear creep of the soil sample will increase and the creep development will not be stable for a long time. In engineering practice, under such a high-stress level, the failure problem needs to be focused on rather than the deformation problem. This phenomenon was not observed in total stress creep, though parameter $A_{\mathrm{s}}$ was increased rapidly under higher stress level

(2) Figure 17 shows the fitting results of the effective stress creep curves of the reconstituted sample under 


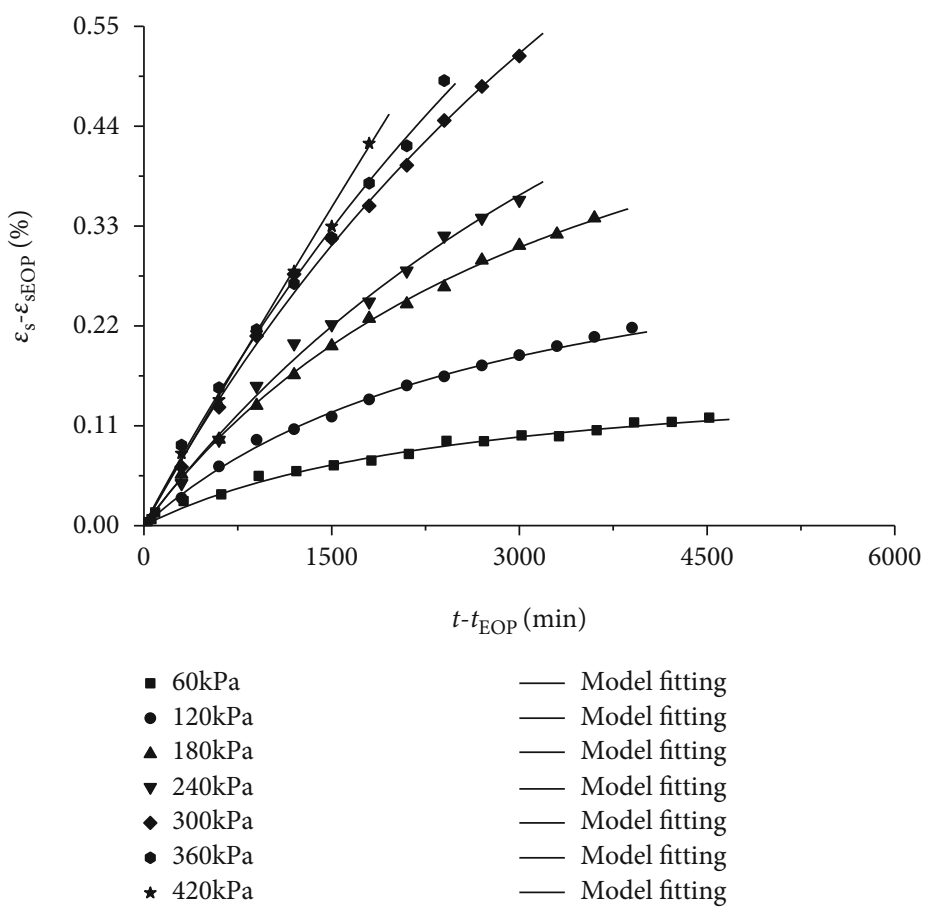

FIGURE 16: Fitting curves of effective stress creep curve of intact soil.

TABLE 7: Hyperbolic model parameters $(\mathrm{kPa})$ and correlation coefficient $R^{2}$ of the triaxial creep test (intact clay).

\begin{tabular}{lcccc}
\hline $\begin{array}{l}\text { Deviatoric } \\
\text { stress }(\mathrm{kPa})\end{array}$ & $\begin{array}{c}\text { Deviatoric } \\
\text { stress level } D_{\mathrm{r}}\end{array}$ & $A_{s}(\%)$ & $B_{s}(\mathrm{~min})$ & $\begin{array}{c}\text { Correlation } \\
\text { coefficient } R^{2}(\%)\end{array}$ \\
\hline 60 & 0.14 & 0.18 & 2575 & 99.14 \\
120 & 0.28 & 0.37 & 2936 & 99.05 \\
180 & 0.42 & 0.67 & 3556 & 99.76 \\
240 & 0.53 & 1.07 & 5787 & 99.71 \\
300 & 0.70 & 1.65 & 6521 & 99.55 \\
360 & 0.84 & 1.88 & 7126 & 99.35 \\
420 & 0.98 & 10.22 & 42239 & 99.72 \\
\hline
\end{tabular}

different stress levels. Model parameters were extracted and given in Table 8 . It shows that the fitting accuracy is higher than $90 \%$, and with the increase of stress level, the value of $B_{\mathrm{s}}$ change very little over the stress level rang of $0 \sim 1$

(3) According to the model parameters given in Tables 7 and 8 , Figure 18 shows the relationship between $A_{\mathrm{s}}$ and $D_{\mathrm{r}}$ (omitting the creep data of high-stress level of $\left.D_{\mathrm{r}}=98 \%\right)$. It can be seen that the model parameters $A_{\mathrm{s}}$ and $D_{\mathrm{r}}$ are in positive correlation. Figure 19 shows the relationship between the model parameters $B_{\mathrm{s}}$ and $D_{\mathrm{r}}$,.For intact clay, the linear relationship is broken at $D_{\mathrm{r}}=0.5$. In both sides of $D_{\mathrm{r}}<0.5$ and $D_{\mathrm{r}}>0.5$, the $B_{\mathrm{s}}$ value is linearly incresed with the stress level Dr. The $B_{\mathrm{s}}$ of the reconstituted sample is on an average of $1050 \mathrm{~min}$ for the reconstituted sample

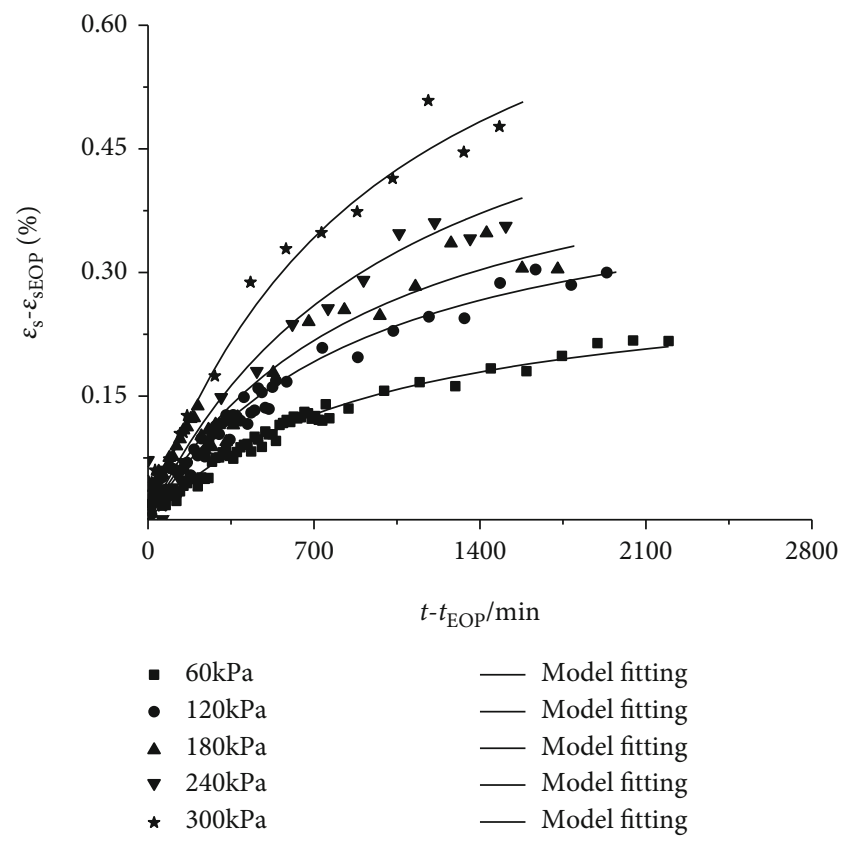

FIgURE 17: Fitting curves of effective stress creep curve of reconstituted soil.

\section{Conclusion}

The creep characteristics of the intact and reconstituted samples under different stress levels were studied through indoor triaxial shear creep tests. A hyperbolic creep model was used to fit the creep curves, and the values of model parameters were discussed. The main conclusions are as follows: 
TABLE 8: Hyperbolic model parameters and correlation coefficient $R^{2}$ of the triaxial creep test (reconstituted clay).

\begin{tabular}{lcccc}
\hline $\begin{array}{l}\text { Deviatoric } \\
\text { stress }(\mathrm{kPa})\end{array}$ & $\begin{array}{c}\text { Deviatoric } \\
\text { stress level } D_{\mathrm{r}}\end{array}$ & $A_{s}(\%)$ & $B_{s}(\mathrm{~min})$ & $\begin{array}{c}\text { Correlation } \\
\text { coefficient } R^{2}(\%)\end{array}$ \\
\hline 60 & 0.18 & 0.30 & 949.72 & 97.36 \\
120 & 0.36 & 0.44 & 891.90 & 97.48 \\
180 & 0.55 & 0.50 & 909.39 & 90.36 \\
240 & 0.73 & 0.65 & 1353.53 & 96.93 \\
300 & 0.91 & 0.82 & 976.00 & 97.97 \\
\hline
\end{tabular}

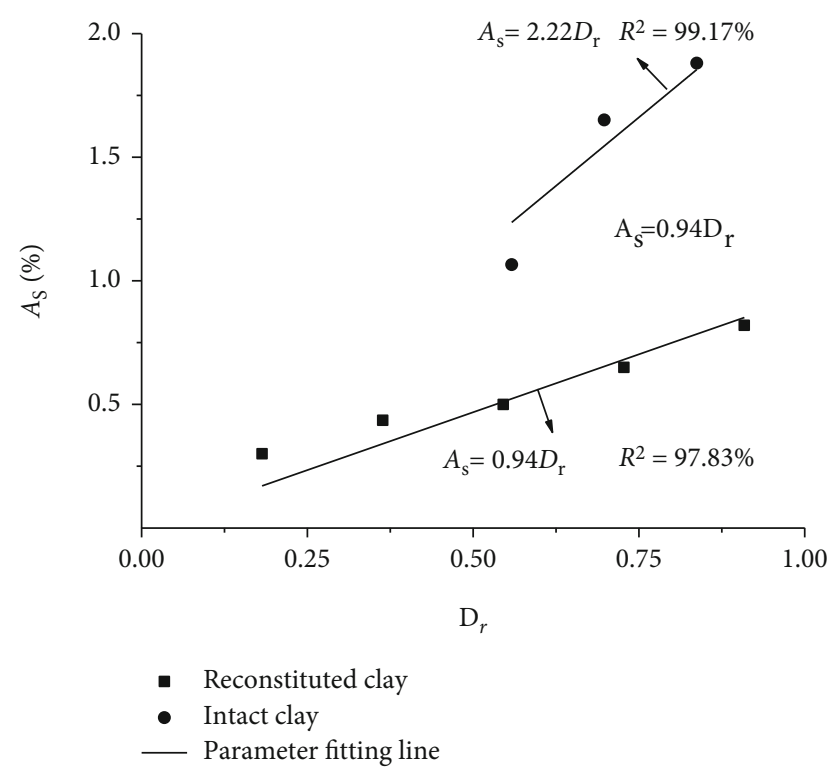

Figure 18: Model parameter $A_{\mathrm{s}}$ versus deviatoric stress level $D_{\mathrm{r}}$.

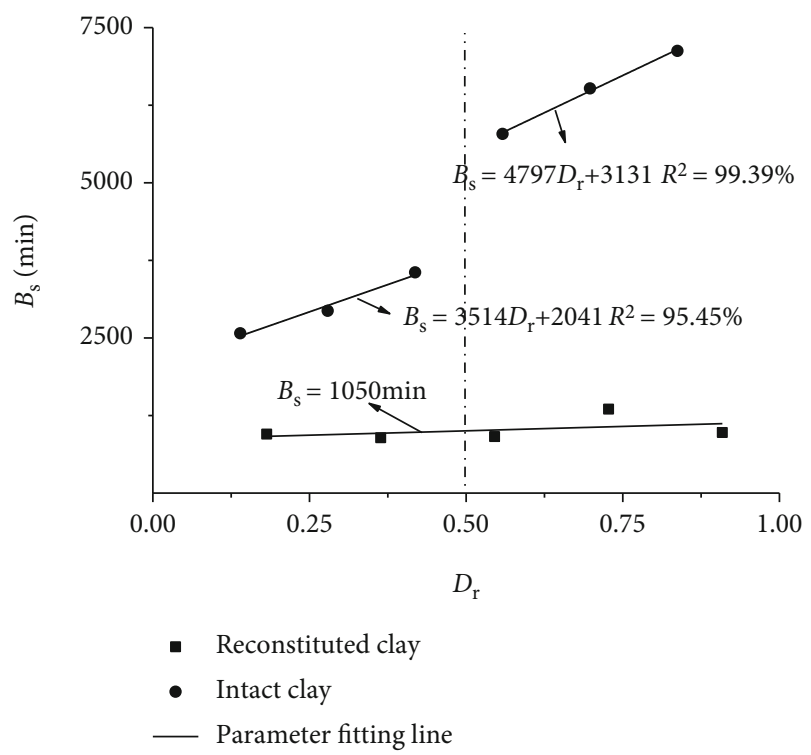

FIgURE 19: Model parameter $B_{\mathrm{s}}$ versus deviatoric stress level $D_{\mathrm{r}}$.

(1) The creep behaviour of the studied clay under triaxial shear stress, in both intact sample and reconstituted sample, shows nonlinear variation feature;
The amount of creep and the time of creep both increase with stress level. Under the same stress state, the creep of reconstituted sample devlops less than that of the intact sample, indicating that, for practical use, the creep parameters should be tested on intact samples which contain the original soil structure

(2) The hyperbolic creep model is suitable for describing the creep behaviour of the saturated clay either in intact or in reconstituted condition. For both total stress creep analysis and effective stress creep analysis, the model fit well, indicating thatthe hyperbolic creep model is adaptive. The model parameters $A_{s}$ and $B_{\mathrm{s}}$ both show a linear correlation with the stress level $D_{\mathrm{r}}$. Under the same stress level, the final triaxial creep strain $A_{\mathrm{s}}$ However, while $B_{\mathrm{s}}$ of the intact sample increases with stress level, $B_{\mathrm{s}}$ of the reconstituted sample changes very little and can be treated as a constant for a given clay

(3) While using the total stress creep analysis, both $A_{\mathrm{s}}$ and $B_{\mathrm{s}}$ of the hyperbolic model show better linear correlation with the stress level $D_{\mathrm{r}}$ and the total stress creep analysis can be a potential recommendation for engineering application.

\section{Data Availability}

All data generated during the study.

\section{Conflicts of Interest}

The author declares no conflict of interests related to this article.

\section{Acknowledgments}

This project is supported by the National Natural Science Foundation of China (Grant No. 51878616), the Fundamental Scientific Research Funds for Universities of Zhejiang Province (Grant No. FRF20QN001), and the Natural Science Foundation of Zhejiang Province (LHY19E090002).

\section{References}

[1] X. P. Chen, H. H. Zhu, F. Z. Zhang, and B. Zhang, "Experimental study on time-dependent deformation of soft soil," Chinese Journal of Rock Mechanics and Engineering, vol. 24, no. 12, pp. 2142-2148, 2005.

[2] S. C. Wu, M. Y. Hu, Y. Zhang, B. Xiao, and K. L. Chen, "Experimental study of secondary consolidation characteristics of silty clays," Journal of Hydraulic Engineering, vol. 46, no. s1, pp. 338-342, 2015.

[3] X. W. Zhang, Creep Characteristics and Disturbed State Model of Structural Soft Soil, Jilin University, 2010.

[4] X. S. Liu, D. Zhao, and W. S. Wang, "Experimental study on the influence of intact structure on dynamic deformation characteristics of saturated sand," Journal of Hydraulic Engineering, vol. 24, no. 2, pp. 32-42, 1993. 
[5] Y. X. Gong, Experimental Study on Consolidation Creep Characteristics of Soft Clay under Different Drainage Conditions, Wuhan University of science and technology, 2010.

[6] W. B. Zhang, Y. L. Xie, and X. H. Yang, "One dimensional secondary consolidation characteristics of compacted loess," Chinese Journal of Geotechnical Engineering, vol. 29, no. 5, pp. 765-768, 2007.

[7] Y. B. Gao, H. H. Zhu, G. B. Ye, and C. Xu, "The investigation of the coefficient of secondary compression $\mathrm{C}_{\mathrm{a}}$ in oedometer tests," Chinese Journal of Geotechnical Engineering, vol. 26, no. 4, pp. 459-463, 2004.

[8] L. L. Zeng, Z. X. Hong, S. Y. Lui, and F. Q. Chen, "Variation law and quantitative evaluation of secondary consolidation behavior for remolded clays," Chinese Journal of Geotechnical Engineering, vol. 34, no. 8, pp. 1496-1500, 2012.

[9] Z. C. Wang, L. P. Qiao, and S. C. Li, "Study on the influence of load level and void ratio on the secondary compression properties of soil," China Civil Engineering Journal, vol. 46, no. 1, pp. 112-118, 2013.

[10] S. C. Wu, Experimental Study on Time Deformation Characteristics of Remolded Saturated Silty Clay, Zhejiang University of technology, 2016.

[11] J. H. Yin, "Non-linear creep of soils in oedometer tests," Géotechnique, vol. 49, no. 5, pp. 699-707, 1999.

[12] A. Singh and J. K. Mitchell, "General stress-strain-time function for clay," Journal of the clay mechanics and foundation division, vol. 94, pp. 21-46, 1968.

[13] G. Mesri, E. F. Cordero, D. R. Shields, and A. Castro, "Shear stress-strain-time behaviour of clays," Geotechnique, vol. 31, no. 4, pp. 537-552, 1981.

[14] P. Z. Lu, J. Zeng, and Q. Sheng, "Creep test and empirical model study of soft clay," Rock and Soil Mechanics, vol. 29, no. 4, pp. 1041-1044, 2008.

[15] B. Xiao, Study on Creep Characteristics and Creep Model of Remolded Silty Clay, Zhejiang University of technology, 2017.

[16] G. Mesri and P. M. Godlewaki, "Time and stresscompressibility interrelationship," Journal of Geotechnical Engineering, vol. 103, pp. 417-430, 1977.

[17] G. Mesri, "Effects of friction and thickness on long-term consolidation behavior of Osaka Bay clays ${ }^{1}$," Soils and Foundations, vol. 49, no. 5, pp. 823-824, 2009.

[18] S. A. Degago, G. Grimastad, H. P. Jostad, S. Nordal, and M. Olsson, "Use and misuse of the isotache concept with respect to creep hypotheses A and B," Géotechnique, vol. 61, no. 10, pp. 897-908, 2011.

[19] C. Kelln, J. Sharma, D. Hughes, and J. Graham, “An improved elastic-viscoplastic soil model," Canadian Geotechnical Journal, vol. 45, no. 10, pp. 1356-1376, 2008.

[20] J. H. Yin and J. Graham, "Elastic visco-plastic modelling of one-dimensional consolidation," Géotechnique, vol. 46, no. 3, pp. 515-527, 1996.

[21] D. W. Taylor, Research on Consolidation of Clays, Department of Civil Engineering, MIT, Massachusetts, Cambridge, 1942. 